\title{
Proposed classification for topographic patterns seen after penetrating keratoplasty
}

\author{
Constantinos H Karabatsas, Stuart D Cook, John M Sparrow
}

\begin{abstract}
Aims-To create a clinically useful classification for post-keratoplasty corneas based on corneal topography.

Methods-A total of 360 topographic maps obtained with the TMS-1, from 95 eyes that had undergone penetrating keratoplasty (PKP), were reviewed independently by two examiners in a masked fashion, and were categorised according to a proposed classification scheme. Results-A high interobserver agreement $(88 \%$ in the first categorisation) was achieved. At 12 months post-PKP, a regular astigmatic pattern was observed in $20 / 85$ cases $(24 \%)$. This was subclassified as oval in three cases (4\%), oblate symmetric bow tie in six cases $(7 \%)$, prolate asymmetric bow tie in six cases (7\%), and oblate asymmetric bow tie in five cases $(6 \%)$. An irregular astigmatic pattern was observed in $61 / 85$ cases $(72 \%)$, subclassified as prolate irregular in five cases $(6 \%)$, oblate irregular in four cases $(5 \%)$, mixed in seven cases $(8 \%)$, steep/flat in 11 cases $(13 \%)$, localised steepness in 16 cases $(19 \%)$, and triple pattern in three cases (4\%). Regular astigmatic patterns were associated with significantly higher astigmatism measurements. The surface asymmetry index was significantly lower in the regular astigmatic patterns.

Conclusions-In post-PKP corneas, the prevalence of irregular astigmatism is about double that of regular astigmatism, with a trend for increase of the irregular patterns over time.

(Br F Ophthalmol 1999;83:403-409)
\end{abstract}

Computer assisted videokeratography (CAVK) provides theoretical advantages over keratometry and photokeratoscopy in the assessment of the corneal topography. It has been used to document and classify the topography of normal corneas, ${ }^{1-3}$ as well as corneal surfaces following radial keratotomy ${ }^{4}$ or excimer laser treatment. ${ }^{56}$ The previously reported classifications are, however, inadequate for the great heterogeneity of topographic patterns with irregular astigmatism seen after penetrating keratoplasty (PKP). The large variability of these corneas presents a challenge in classification.

The present study has the following objectives: (a) to develop a useful classification scheme of the topographic patterns seen after penetrating keratoplasty, (b) to correlate topographic patterns with keratometric and refractive data, (c) to understand relations if any, between different astigmatic topographic patterns and refractive errors, and (d) to monitor changes of topographic patterns over the postoperative period in a standardised manner.

\section{Methods}

SELECTION OF SUBJECTS

Three hundred and sixty corneal topographic maps from 95 eyes (88 patients) that had undergone PKP for various causes were prospectively examined.

\section{INSTRUMENTATION}

The instruments used were the TMS-1 (Tomey, software version 1.61) videokeratographer with a 25 ring cone, and the $10 \mathrm{SL} / \mathrm{O}$ keratometer (Carl Zeiss Ltd). Both devices had been calibrated before the beginning of the study and were periodically checked throughout the study.

METHODS OF EXAMINATION

All subjects underwent the following routine examinations, in the same site, under standardised conditions: slit lamp microscopy, manifest refraction, keratometry and videokeratography at every visit. Manifest refraction and keratometric readings were performed by an optometrist; videokeratographic images were taken by an ophthalmologist. Three measurements from each cornea were obtained with both the keratometer and the TMS- 1 . The best videokeratographic image with the most information allowing was selected and processed using the absolute scale. ${ }^{7}$ On all topographic maps the following were recorded: (a) simulated keratometry readings (simk), (b) surface regularity index (SRI), and (c) surface asymmetry index (SAI).

\section{SELECTION OF PICTURES FOR ANALYSIS}

All patients had their topographic maps taken at standardised postoperative intervals $(3,6,9$, and 12 months post-PKP). Depending on the suturing technique used, in some cases interrupted sutures were removed, whereas in others, continuous suture adjustment took place during the follow up. An equal number of topographic maps (four) for each eye were studied. In eight of the 95 cases $(8 \%)$, less than four pictures were assessed, either because patients died during the follow up, missed their appointment, or left the study for other reasons (rejection episode, graft failure). In these cases, data available up to the most recent follow up visit were evaluated. 
PROPOSED QUALITATIVE TOPOGRAPHY

CLASSIFICATION SYSTEM

A classification was derived by one of the investigators (CHK) after monitoring the 360 post-PKP topographic maps during a 2 year period. Certain patterns were identifiable. A proposed classification was designed (Fig 1) with the aid of a computer drawing software (Microsoft draw) and used throughout in the evaluation of the maps. All topographic maps were initially reviewed by the primary investigator $(\mathrm{CHK})$ and classified according to the configuration of the colours on the absolute scale. Because of the qualitative nature of the classification, and in order to reduce investigator's bias, each map was categorised according to two features: the corneal profile and the type of astigmatism.

(A) The corneal profile

This refers to the contour of a cross section of the cornea. The examined corneas could be allocated to one of three categories-prolate, oblate, or mixed.

(1) Prolate: the cornea appears to have increased dioptric power (steeper) centrally than at the periphery.

(2) Oblate: a cornea of decreased power (flatter) centrally than peripherally.

(3) Mixed: features of both oblate and prolate shape are present at different corneal areas.

(B) The type of astigmatism

According to its pattern characteristics, the astigmatism was classified as follows:

(1) Oval pattern: when the ratio of the shortest to the longest diameter at the colour zone chosen for pattern reading, is less than two thirds. ${ }^{1}$

(2) Regular astigmatic pattern: this is the pattern seen when the two principal meridians are oriented at approximately right angles to each other. Regular astigmatism is usually presented topographically by a bow tie pattern that can be symmetrical or asymmetrical (Figs 1 and 2). Any pattern presenting with an angle $\alpha$ between the axis of the two halves of the bow tie of less than $20^{\circ}$ (Fig 2), was defined as regular astigmatic.

(2a) Regular symmetric bow tie pattern: this type, in addition to the above criteria for regularity, shows also the following characteristics: (a) the ratio $\mathrm{X}_{1} / \mathrm{X}_{2}$ is two thirds or more, and/or (b) the difference in power between the two limbs of the bow $|\mathrm{A}-\mathrm{B}|$ is 1 dioptre or less, when measured with the cursor at a radius of $1.5 \mathrm{~mm}$ from the centre (Fig 2).

(2b) Regular asymmetric bow tie pattern: a regular astigmatic pattern was defined as asymmetric, when the following additional criteria were met: (a) $X_{1} / X_{2}$ ratio less than two thirds, and/or (b) $|\mathrm{A}-\mathrm{B}|>1 \mathrm{D}$ (Fig 2). Topographically this is presented as a "dumbbell"-shaped (Fig 1).

(3) Irregular astigmatic patterns: if the two steepest semimeridia were at an angle $\alpha$ to each other which was greater than $20^{\circ}$, this astigmatism was defined as irregular. This is represented topographically as a "bi-oblique" bow tie pattern (Fig 1).

A combination of the above criteria, resulted in the identification of five subclassifications of regular astigmatism. These were: (1) oval pattern (Fig 3B), (2) prolate symmetric bow tie (PSBT) (Fig 3C), (3) prolate asymmetric bow

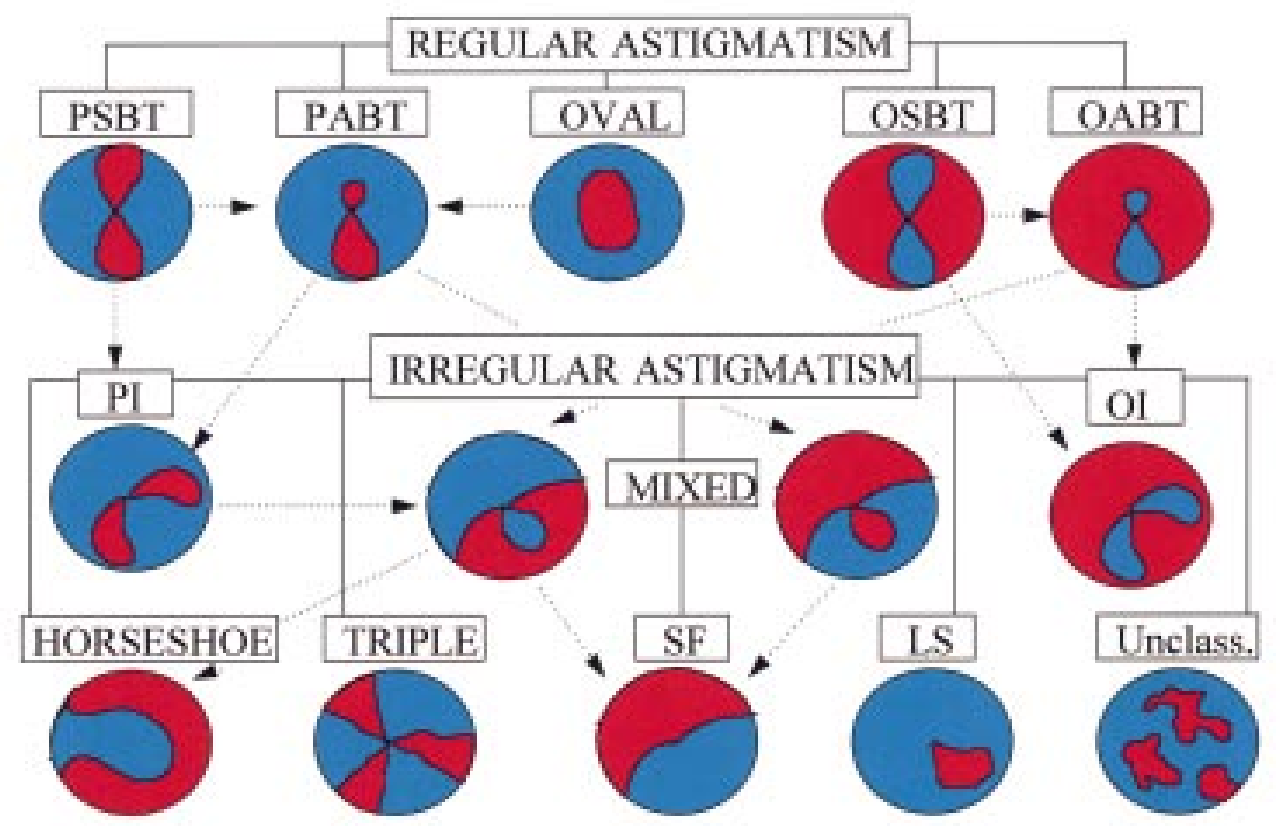

Figure 1 Proposed videokeratography pattern classification scheme. PSBT=prolate symmetric bow tie, PABT=prolate asymmetric bow tie, $O S B T=$ oblate symmetric bow tie, $O A B T=$ oblate asymmetric bow tie, $P I=$ prolate irregular, $O I=$ oblate irregular, $S F=$ steep/flat, $L S=$ localised steep. Most of the patterns can be seen as a continuum, with some of them changing into different patterns (arrows) after manipulation of post-PKP astigmatism, by removal or adjustment of sutures. Blue and red colours imply flat and steep areas respectively, as in the conventional topographic map representation. 

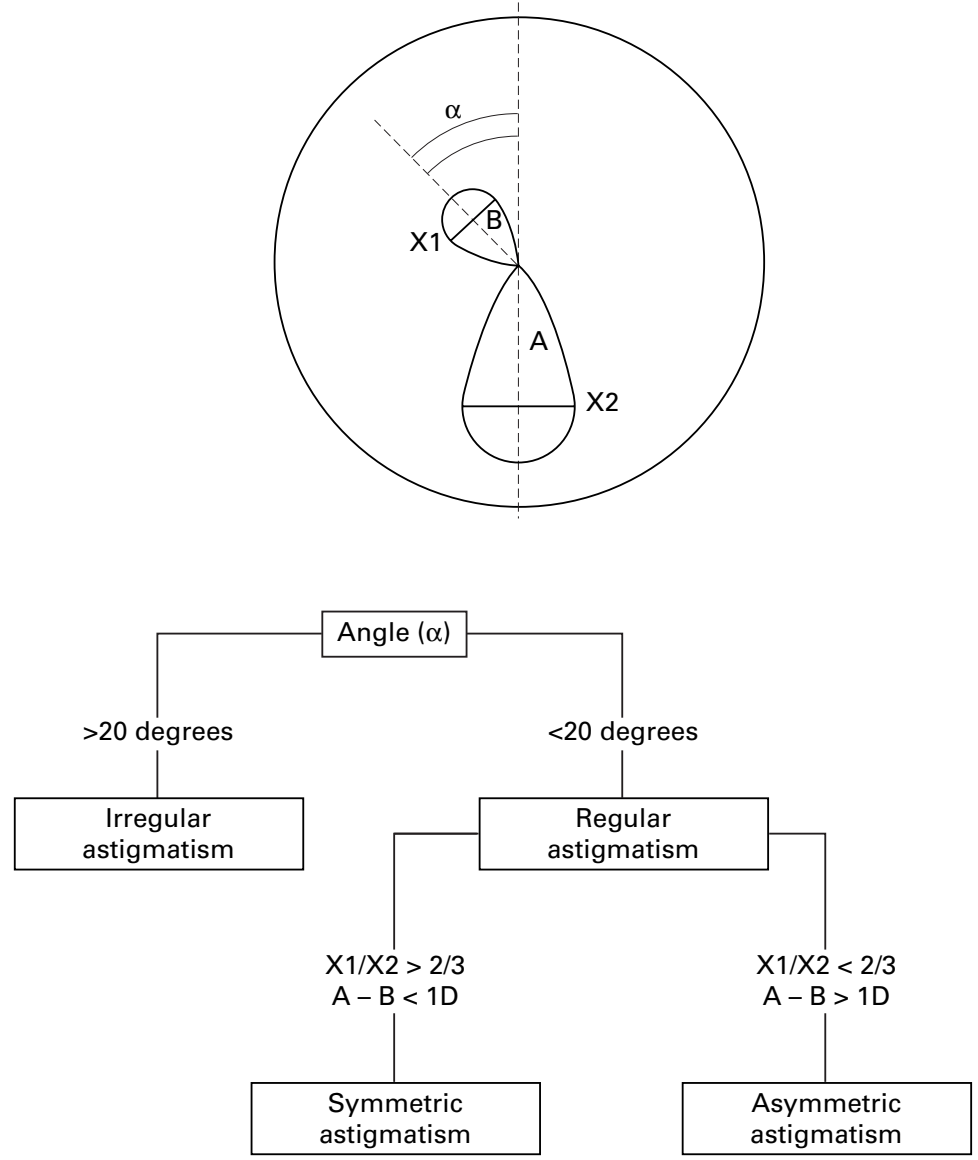

Figure 2 Schematic illustration of the criteria for determination upon regularity and symmetricity of a topographic pattern. Firstly, a line bisecting the two lobes of the bow tie $i$ is drawn. If the skewing between the two is greater than $20^{\circ}$ the pattern is described as irregular, otherwise as regular. Regular patterns are further subdivided into symmetric and asymmetric according to the difference in width of the lobes $|X 1-X 2|$, and/or difference in their dioptric power $|A-B|$ at a radius of $1.5 \mathrm{~mm}$ from the centre. tie (PABT) (Fig 3D), (4) oblate symmetric bow tie (OSBT) (Fig 3E), and (5) oblate asymmetric bow tie (OABT) pattern (Fig 3F). Irregular astigmatism was subclassified accordingly into: (1) prolate irregular (PI) (Fig 4A), (2) oblate irregular (OI) (Fig 4B), and mixed pattern (Figs $4 \mathrm{C}$ and D).

In addition to these, the following four characteristic patterns (subclassified under the irregular astigmatic patterns) were identified, by objective criteria.

(1) Steep/flat (SF) pattern: the cornea was steeper on one side, becoming progressively flatter towards the other side (Fig 4E).

(2) Localised steepness (LS) pattern: an eccentric area of localised steepness, up to one quarter of corneal diameter size could be seen, surrounded by cornea of relatively lower power (flatter) (Fig 4F).

(3) Triple pattern: characteristically, three distinct areas of radial steepening were identifiable (Fig 5A).

(4) "Horseshoe" pattern: in this configuration, a C-shaped area of increased corneal power could be identified at the graft host interface (Fig 5B).

Finally, two more groups of maps were suggested by the classification; one including the "non-astigmatic" (round) corneas, and the "unclassified" group (Fig 3A). Therefore, the final classification includes 14 patterns (Table 1, Fig 1).

A second ophthalmologist (SDC), after becoming familiar with the proposed classification, reviewed all topographic maps, independently of the first observer in a masked fashion.

DATA COLLECTION AND STATISTICAL ANALYSIS All data (quantitative indices and qualitative classification after picture review) were entered into an Excel spreadsheet (Microsoft, Seattle, WA, USA). Files were statistically analysed with

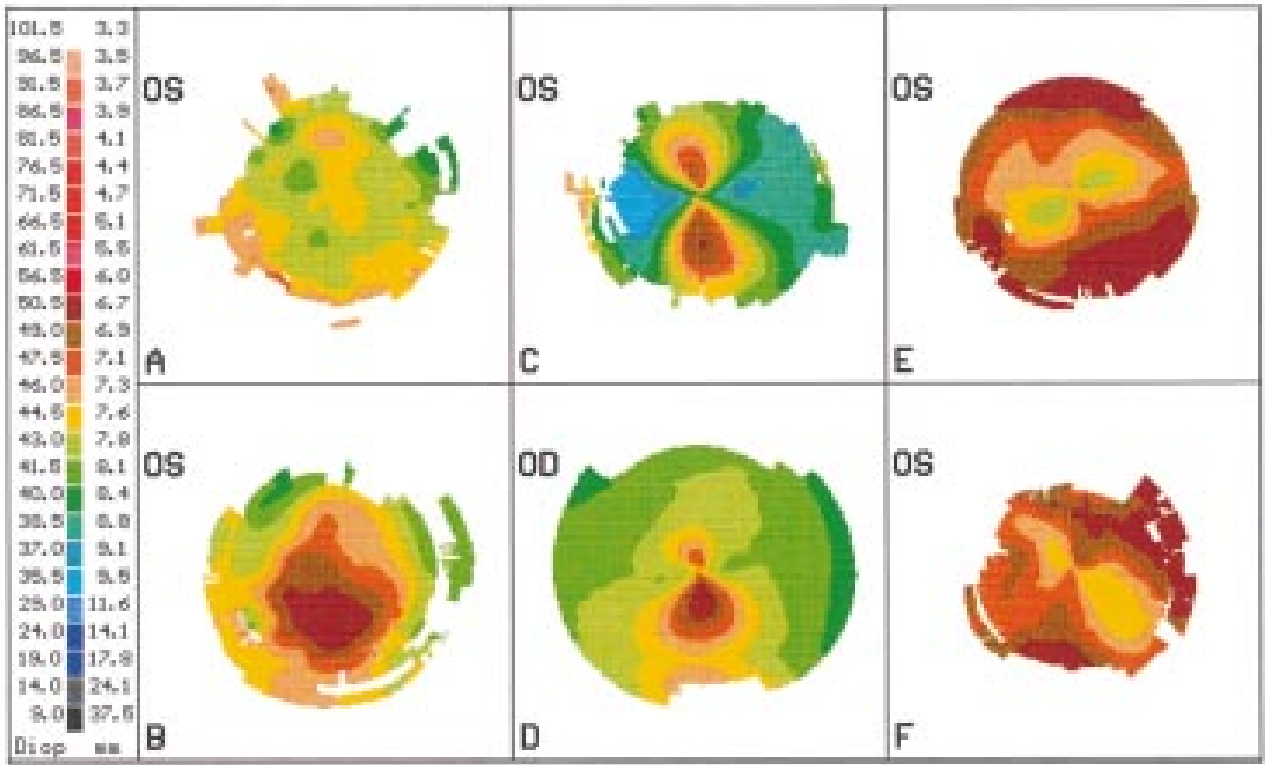

Figure 3 Examples of different topographic patterns. (A) Unclassified pattern, (B) oval (prolate) astigmatic pattern with central area of steepening; $(C)$ prolate symmetric bow tie (PSBT) pattern; (D) prolate asymmetric bow tie (PABT) pattern; (E) oblate symmetric bow tie (OSBT) pattern; (F) oblate asymmetric bow tie (OABT) pattern. 


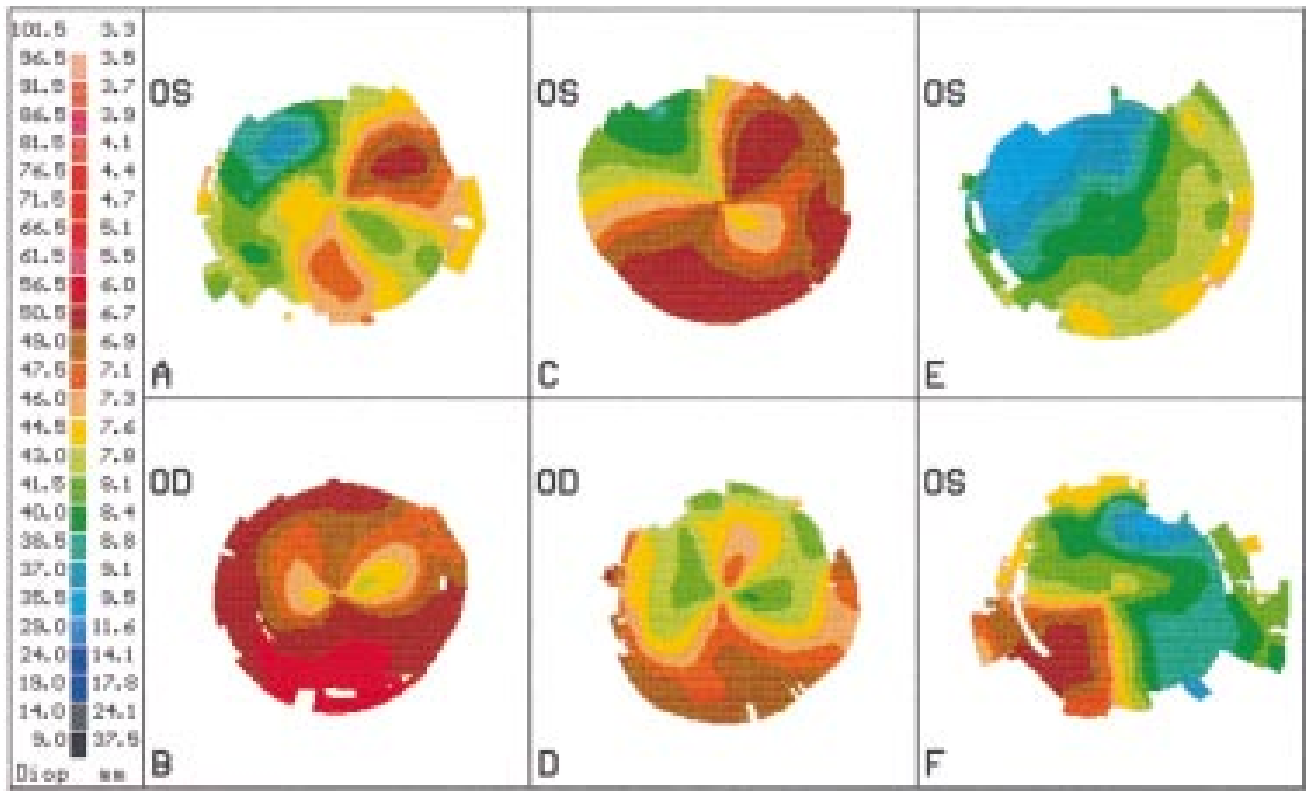

Figure 4 Examples of different topographic patterns of irregular astigmatism. (A) Prolate irregular (PI) pattern; (B) oblate irregular (OI) pattern; (C) and (D) mixed irregular patterns; (E) steep/flat (SF) pattern; (F) localised steep (LS) patterns.

the MINITAB statistics package, version 10.X (Minitab Inc, Reading, MA, USA). Separate analysis of topographic patterns distribution were performed for each time point $(3,6,9$, and 12 months post-PKP). Percentages have been rounded to the nearest whole number. For comparison of astigmatic data between topographic groups, only the 12 month values were analysed. Small numbers $(<5)$ in some of the nonastigmatic stratified groups did not permit meaningful statistical analysis for these groups alone. Therefore, differences in means were compared with distribution-free statistical techniques (Kruskal-Wallis test) for the rest of the subgroup comparisons. Differences between the pooled regular and irregular groups for which suitable sample sizes are available, were tested with the one way ANOVA test. Statistical significance for all tests was at the 0.05 level.

\section{Results}

The total number of topographic maps that were analysed was 360 . Of these, seven maps

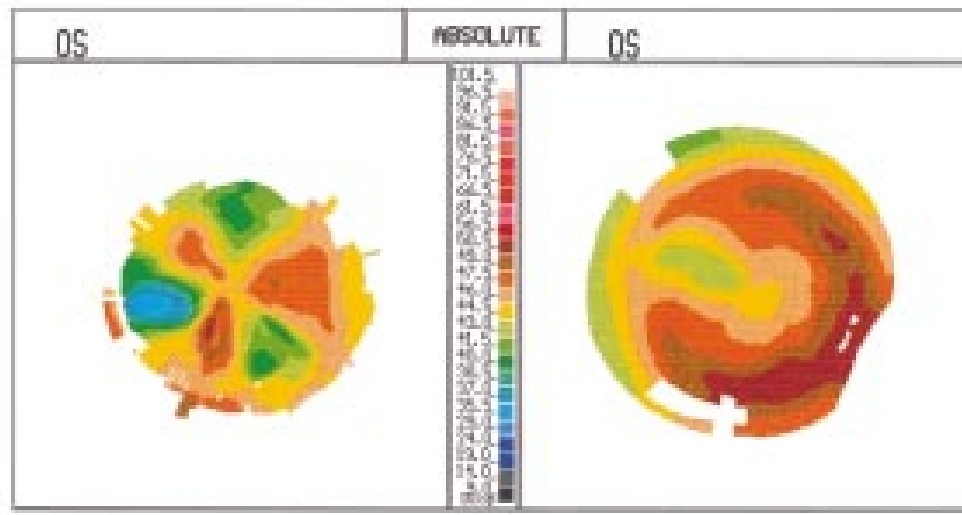

Figure 5 Examples of different topographic patterns of irregular astigmatism. (Left) Triple pattern; (right) "horseshoe" pattern.
Table 1 Patterns of the proposed classification for post-keratoplasty corneas

1 Non-astigmatic corneas

2 Regular astigmatism

(a) oval

(b) prolate symmetric bow tie (PSBT)

(c) prolate asymmetric bow tie (PABT)

(d) oblate symmetric bow tie (OSBT)

(e) oblate asymmetric bow tie (OABT)

3 Irregular astigmatism

(a) mixed

(b) prolate irregular $(\mathrm{PI})$

(c) oblate irregular (OI)

(d) "horseshoe" pattern

(e) "triple" pattern

(f) steep/flat (SF)

(g) localised steep (LS)

(h) unclassified

( $2 \%)$ were considered by both examiners as maps of very poor quality, with unreliable data. Therefore the final number of topographic maps left for classification was 353 .

AGREEMENT BETWEEN EXAMINERS

All maps were independently classified by two observers. Exact agreement was achieved in $309 / 353$ cases (88\%). Disagreements were then reviewed by both observers together, and a consensus grade was agreed for a further 13 images. The total number of agreed grades was thus $322 / 353(91 \%)$.

DISTRIBUTION OF TOPOGRAPHIC PATTERNS AND CHANGE OVER TIME

Distributions of the various patterns at the 3,6, 9, and 12 months post-PKP intervals are shown in Table 2. Depending on the time interval, a regular astigmatic pattern was seen in a percentage between $24 \%$ (at 12 months post-PKP) and $39 \%$ (at 3 months post-PKP). The percentage of irregular patterns was between $61 \%$ (at 9 months) and $72 \%$ (at 12 months). Although the percentages of regular 
Table 2 Distribution of topographic patterns seen at different time intervals post-PKP. For maps where no agreement was achieved, the classification of investigator 1 was considered

\begin{tabular}{lcccc}
\hline Topographic patterns & $\begin{array}{l}3 \text { months } \\
\text { No (\%) }\end{array}$ & $\begin{array}{l}6 \text { months } \\
\text { No(\%) }\end{array}$ & $\begin{array}{l}9 \text { months } \\
\text { No (\%) }\end{array}$ & $\begin{array}{l}12 \text { months } \\
\text { No (\%) }\end{array}$ \\
\hline I Non-astigmatic & - & $2(2)$ & $4(5)$ & $4(5)$ \\
II Regular astigmatism & $36(39)$ & $32(35)$ & $29(35)$ & $20(24)$ \\
$\quad$ Oval & $4(4)$ & $3(3)$ & $6(7)$ & $3(4)$ \\
PSBT & $5(5)$ & $7(8)$ & $2(2)$ & - \\
PABT & $16(17)$ & $11(12)$ & $8(10)$ & $6(7)$ \\
OSBT & $2(2)$ & - & $5(6)$ & $6(7)$ \\
OABT & $9(10)$ & $11(12)$ & $8(10)$ & $5(6)$ \\
III Irregular astigmatism & $56(61)$ & $58(63)$ & $51(61)$ & $61(72)$ \\
PI & $16(17)$ & $9(10)$ & $10(12)$ & $5(6)$ \\
OI & - & $2(2)$ & $2(2)$ & $4(5)$ \\
Mixed & $6(7)$ & $3(3)$ & $7(8)$ & $7(8)$ \\
SF & $8(9)$ & $12(13)$ & $9(11)$ & $11(13)$ \\
LS & $11(12)$ & $15(16)$ & $8(10)$ & $16(19)$ \\
Triple & $7(8)$ & $6(7)$ & $3(4)$ & $3(4)$ \\
Horseshoe pattern & $1(1)$ & $2(2)$ & $3(4)$ & $3(4)$ \\
Unclassified & $7(8)$ & $9(10)$ & $9(11)$ & $12(14)$ \\
Total & 92 & 92 & 84 & 85 \\
\hline
\end{tabular}

Percentages have been rounded off to the nearest whole number.

and irregular astigmatism remain quite stable over the first 9 months, at the 12 month follow up visit an increase of the irregular astigmatism percentage is noted (from $61 \%$ at 9 months, to $72 \%$ at 12 months), together with an associated decrease of the combined regular patterns (from $35 \%$ at 9 months to $24 \%$ at 12 months).

RELATION BETWEEN TOPOGRAPHIC PATTERNS

AND ASTIGMATISM

For correlation between topographic patterns and astigmatism, the 12 months data were considered (Table 3).

REFRACTIVE ASTIGMATISM (CYL D)

The Kruskal-Wallis test demonstrated no statistically significant difference $(p=0.244)$ for refractive astigmatism among subgroups of topographic patterns. The least refractive astigmatism was seen in the triple pattern (mean 1.25 (SD 0.66)) and in the nonastigmatic pattern (1.62 (0.85)); the most refractive astigmatism was recorded for the OABT pattern (5.35 (4.47)). The pooled regular astigmatism group was also not found to be different from the pooled irregular astigmatism group in terms of refractive astigmatism ( $\mathrm{p}=0.175$, ANOVA).

KERATOMETRIC ASTIGMATISM

There were no statistically significant differences among topographic patterns when tested separately ( $\mathrm{p}=0.476$, Kruskal-Wallis), or as pooled broader categories $(\mathrm{p}=0.185$, ANOVA for combined regular $v$ irregular astigmatism). Apart from the non-astigmatic group, the horseshoe pattern was the one showing the least keratometric astigmatism (2.0 (0.69) D). The most keratometric astigmatism was recorded in the OI pattern (7.2 (2.23) D) and the OABT pattern $(6.93(5.90) \mathrm{D})$.

TOPOGRAPHIC ASTIGMATISM (SIMK)

No differences in mean topographic astigmatism among the subgroups with adequate sample size were found ( $\mathrm{p}=0.368$, Kruskal-Wallis). Among subgroups, OABT pattern showed the most astigmatism (6.84 (4.83) D), whereas horseshoe (1.63 (0.30) D) and non-astigmatic patterns (1.9 (1.15) D) the least. However, when tested as pooled groups, the regular and irregular astigmatic groups were different $(\mathrm{p}=0.05$, ANOVA), with the regular astigmatism exhibiting greater values (5.09 (4.12) v 3.70 (2.15), Table 3).

RELATION BETWEEN TOPOGRAPHIC PATTERNS AND QUANTITATIVE INDICES

SRI

There were differences among some of the topographic groups for SRI $(p=0.04)$. Small numbers however on each subgroup $(\mathrm{n}<10)$ do not permit a further analysis with the Wilcoxon signed rank method. ${ }^{8}$ Moreover, although SRI was lower in the pooled regular astigmatic group $(1.24(0.83))$ than in the pooled irregular astigmatic group $(1.70(1.37))$, the difference was not significant ( $p=0.150$, ANOVA).

$S A I$

For SAI measurements, there were statistically significant differences among stratified topographic groups when tested separately ( $\mathrm{p}=0.007$, Kruskal-Wallis) or as pooled broader categories (regular $v$ irregular patterns, $p=0.05$, ANOVA). SAI was less for the regular than for the irregular patterns $(0.91$ (0.59) v 1.23 (0.65), Table 3). Furthermore, when comparing the combined "symmetric astigmatic group" (PSBT and OABT) against the "asymmetric astigmatic group" (PABT and OABT), the difference was approaching statistical significance $(\mathrm{p}=0.06$ with $-0.09,0.84$ $96.1 \%$ CI for the difference, Mann-Whitney test).

Table 3 Comparison of topographic patterns, in relation to astigmatism and quantitative indices

\begin{tabular}{llllll}
\hline & $\begin{array}{l}\text { Refractive } \\
\text { astigmatism } \\
\text { Mean (SD) }\end{array}$ & $\begin{array}{l}\text { Keratometric } \\
\text { astigmatism } \\
\text { Mean (SD) }\end{array}$ & $\begin{array}{l}\text { Topographic } \\
\text { astigmatism } \\
\text { (simk) } \\
\text { Mean (SD) }\end{array}$ & $\begin{array}{l}\text { SRI } \\
\text { Mean (SD) }\end{array}$ & $\begin{array}{l}\text { SAI } \\
\text { Mean (SD) }\end{array}$ \\
Topographic pattern & $1.67(0.76)$ & $1.17(0.99)$ & $1.61(0.85)$ & $0.82(0.39)$ & $0.60(0.27)$ \\
\hline I Non-astigmatic & $4.20(2.98)$ & $5.08(3.21)$ & $5.93(3.92)$ & $1.63(1.26)$ & $0.97(0.61)$ \\
II Regular astigmatism & $2.17(1.22)$ & $2.96(3)$ & $2.70(1.97)$ & $1.61(1.32)$ & $1.06(0.49)$ \\
$\quad$ Oval & $4.09(1.81)$ & $7(2.57)$ & $8.18(4.63)$ & $1.82(1.04)$ & $1.01(0.54)$ \\
PSBT & $4.41(3.50)$ & $5.45(2.76)$ & $6.22(3.28)$ & $2.07(1.48)$ & $1.20(0.76)$ \\
PABT & $4.81(2.99)$ & $4.63(3.70)$ & $6.82(5.79)$ & $1.08(0.59)$ & $0.73(0.59)$ \\
OSBT & $4.62(2.79)$ & $5.65(3.17)$ & $5.72(2.88)$ & $1.49(1.24)$ & $0.90(0.38)$ \\
OABT & $3.37(2.38)$ & $4.03(2.87)$ & $3.98(2.47)$ & $2.06(1.67)$ & $1.44(0.88)$ \\
III Irregular astigmatism & $4.61(2.49)$ & $5.37(3.14)$ & $5.20(2.49)$ & $1.78(1.25)$ & $1.09(0.57)$ \\
Prolate irregular (PI) & $5.46(1.51)$ & $6.47(2.07)$ & $5.70(2.64)$ & $2.50(2.21)$ & $1.22(0.98)$ \\
Oblate irregular (OI) & $4.22(2.92)$ & $5.56(3.66)$ & $4.83(2.73)$ & $1.96(1.82)$ & $1.19(0.77)$ \\
Mixed & $2.39(1.62)$ & $2.87(1.39)$ & $3.43(1.87)$ & $1.96(1.79)$ & $1.70(0.99)$ \\
Steep/flat (SF) & $2.50(1.77)$ & $3.02(2.14)$ & $3.34(2.57)$ & $2.10(1.57)$ & $1.68(0.82)$ \\
Localised steep (LS) & $3.78(2.95)$ & $2.91(0.61)$ & $2.70(1.54)$ & $1.11(0.38)$ & $0.94(0.47)$ \\
Triple & $2.08(1.61)$ & $2.20(0.82)$ & $2.26(1.25)$ & $0.97(0.54)$ & $0.97(0.42)$ \\
Horseshoe & $3.37(2.35)$ & $4.58(3.91)$ & $4.23(2.43)$ & $3.19(1.92)$ & $1.78(1.12)$ \\
$\quad$ Unclassified & & & &
\end{tabular}




\section{Discussion}

We present a new classification of post-PKP topographic patterns, with an acceptable observer agreement level, a prerequisite for clinical use. The corneas examined in this series are representative of a PKP population, including individuals with a variety of preoperative diagnoses and astigmatism amplitude, different ages and sex, while donor buttons had been sutured with different techniques. Three previous studies ${ }^{1-3}$ have described the variations of topographic patterns seen in normal corneas. Three further reports have studied the topographic patterns seen after radial keratotomy $(\mathrm{RK})^{4}$ and after photorefractive keratectomy (PRK). ${ }^{56}$ As far as we are aware, apart from two abstracts, ${ }^{9}{ }^{10}$ studies on topographic classifications for post-PKP corneas have not been previously reported. The classifications for normal, post-RK and post-PRK corneas are inadequate for the variability of topographic patterns seen after PKP. The shape of a post-graft cornea is invariably different from the prolate shape seen in $100 \%$ of normal corneas, ${ }^{2}$ but in only $3 \%$ of corneas following RK. ${ }^{4}$ In the present study, an equal percentage $(21 \%)$ of prolate and oblate shape corneas were seen, with the mixed prolate/oblate configuration presenting more often (58\%). Tripoli et $a l^{9}$ also cite an equal percentage of prolate and oblate shapes (31\%). The comparison with results of previous series is quite difficult, mainly because of the lack of generally accepted classification criteria. There is clearly a need for establishment of such criteria, applicable to both normal and pathological corneas. We used the absolute scale for our classification. Bogan et $a l^{24}$ have used the normalised scale, whereas Hersh et al ${ }^{6}$ used colour bins of $0.5 \mathrm{D}$. We believe that a single consistent scale with standardised colours should be used to monitor changes over time and any qualitative classification should be based on the absolute scale. It has been suggested that a $1.5 \mathrm{D}$ interval scale such as the absolute scale provides the best combination of sensitivity and the widest range of coverage of powers that are found on corneas after surgery, and is adequate for recognising pathology. ${ }^{11}$

It is quite common to find different definitions of "irregular astigmatism", by various investigators. Bogan et $a l^{2}$ defined as irregular any pattern that could not be identified as round, oval, or bow tie. Wilson et al ${ }^{11}$ determined irregular astigmatism whenever three or more of power interval colours with the absolute scale, were irregularly distributed on the map within $1.5 \mathrm{~mm}$ of the vertex. Hersh et $a l^{6}$ characterised as "irregularly irregular" images showing an area more than $0.5 \mathrm{~mm}$ in size and more than $0.5 \mathrm{D}$ in power from other areas at the same radius from the optical centre. In our study, irregular astigmatism was defined as any astigmatism with the principal axes showing an angle to each other greater than $20^{\circ}$, and was subclassified in eight patterns. According to previous studies "irregular astigmatism" can be found in $6-7 \%$ of normal and post-RK corneas, ${ }^{2-4}$ and in $13.8 \%$ of post-PRK cases. ${ }^{6}$ In the current study "irregular patterns" were seen about twice as often as "regular patterns" $(30 \% v 59 \%$ of the 353 maps examined). Change of the incidences over the postoperative period was observed, with a tendency for increase of the irregular patterns and conversely decrease of the regular patterns over time. This is likely to be a result of the healing process and postoperative suture manipulation.

Although some of the irregular patterns, such as the triple and the horseshoe pattern have not been described in conditions other than post-PKP, other images such as the PI (Fig 4A) and mixed patterns (Fig 4C, D) can also be associated with conditions such as pterygium, peripheral gutter, localised thinning, ${ }^{12}$ or pellucid marginal corneal degeneration and keratoglobus. ${ }^{13}$ The classification chart suggests that some patterns may evolve from others (indicated by the arrows in Fig 1), whereas other patterns such as the triple, LS, and unclassified do not belong in any kind of continuum. The spectrum of post-PKP topographic patterns may be explained by variations in corneal hydration, changes in forces that develop at the graft-host interface secondary to epithelial and stromal wound healing and remodelling, ${ }^{12}$ or the effect of sutures. ${ }^{14}$

Of the quantitative indices, no association was found between SRI and regular or irregular astigmatic groups. SRI was designed statistically to allow for local corneal power fluctuations along each semimeridian. ${ }^{15}$ The SRI algorithms determine as irregularity the difference in power gradient between successive mire pairs. Therefore, regularity is defined differently to our classification. Moreover, SRI algorithms compute data only from the central 10 photokeratoscope mires (central 3-4 $\mathrm{mm}$ of the cornea). However, we based our classification on interpretation of topographic maps covering the whole donor corneal surface. Conclusively, patterns such as LS, horseshoe, $\mathrm{SF}$, or mixed could be classified as irregular, but on the other hand may show low SRI values because of a relatively homogeneous central corneal power. In fact, low mean SRI values, but higher than in normals, were observed with the horseshoe, mixed, and SF patterns $(0.87,0.88,1.11$ respectively), lower than the average SRI of the regular astigmatic group (1.24).

Significantly lower SAI values were observed with regular astigmatic patterns. Furthermore, topographic maps classified as asymmetric (PABT, OABT), showed higher SAI value than symmetric patterns (PSBT, OSBT). This index appeared to be more useful than SRI in distinguishing between regular/irregular and symmetric/asymmetric patterns and it could be used as an additional aid for the qualitative classification of ambiguous cases. The SAI index by summating the absolute differences between dioptric power of symmetric points in opposite semimeridians, checks both radial symmetry as well as regularity of a corneal surface. By definition, SAI would be zero both for a perfect sphere as well as for any surface with a power that is radially symmetrical, but also for a surface with perfectly spherocylindrical regular 
corneal cylinder. ${ }^{16}$ Such a surface according to our criteria $\left(\alpha<20^{\circ}\right)$ would be classified as regular. It follows that the more regular surfaces will exhibit lower SAI values, something confirmed by the findings of our study.

The proposed classification of post-PKP topographic patterns may have potential clinical applications such as: (a) facilitating communication among clinicians and investigators by utilising a standardised scheme; (b) observing changes over time; (c) relating certain topographic patterns to a specific suturing technique or diagnosis; (d) screening for and planning refractive surgery in post-PKP eyes and monitoring the postoperative outcome.

In summary, the following conclusions arise from the present study: (1) 14 topographic patterns after PKP were identifiable; (2) in post-PKP corneas, the incidence of irregular astigmatism is about double that of regular astigmatism. Prolate and oblate patterns are seen in equal proportions; (3) the topographic patterns showed a change over time; a decrease in the regular patterns, with a corresponding increase in the irregular patterns; (4) regular astigmatic patterns were associated with significantly higher astigmatism (simk) measurements; (5) the SRI index failed to demonstrate differences between regular and irregular astigmatic patterns, but the SAI index was significantly lower in the regular astigmatic patterns.

Supported in part by a Greek State Scholarship Foundation (IKY) grant (Mr CH Karabatsas).
1 Dingeldein SA, Klyce SD. The topography of normal corneas. Arch Ophthalmol 1989;107:512-18.

2 Bogan SJ, Waring GO, Ibrahim O, et al. Classification of normal corneal topography based on computer-assisted videokeratography. Arch Ophthalmol 1990;108:945-9.

3 Rabinowitz YS, Yang H, Brickman Y, et al. Videokeratography database of normal human corneas. $\mathrm{Br} \mathcal{F}$ Ophthalmol 1996;80:610-16.

4 Bogan SJ, Maloney RK, Drews CD, et al. Computer-assisted videokeratography of corneal topography after radial keravideokeratography of corneal topography after
totomy. Arch Ophthalmol 1991;109:834-41.

5 Lin DTC, Sutton HF, Berman M. Corneal topography following excimer photorefractive keratectomy for myopia. $\mathcal{F}$ Cataract Refract Surg 1993;19(suppl):149-54.

6 Hersh PS, Schwartz-Goldstein BH, The Summit Photorefractive Keratectomy Topography Study Group. Corneal topography of phase III excimer laser photorefractive keratectomy. Ophthalmology 1995;102:963-78.

7 Maguire LJ, Singer DE, Klyce SD. Graphic presentation of computer-analyzed keratoscope photographs. Arch Ophcomputer-analyzed kerat

8 Brown RA, Swanson Beck J. Medical statistics on personal computers. 2nd ed. London: BMJ Publishing Group, 1994.

9 Tripoli NK, Ibrahim OS, Coggins JM, et al. Quantitative and qualitative topography classification of clear penetrating keratoplasties. Invest Ophthalmol Vis Sci 1990; 30 (suppl): 480 .

10 Baer JC, Kathuria SS, Nirankari VS. Corneal Modeling System (CMS) patterns of astigmatism after keratoplasty
(PK) and correspondence with keratography. Invest Oph(PK) and correspondence with kerat

11 Wilson SE, Klyce SD, Husseini ZM. Standardized colorcoded maps for corneal topography. Ophthalmology 1993; 100:1723-7

12 O'Brart DPS, Corbett MC, Rosen ES. The topography of corneal disease. Eur f Implant Ref Surg 1995;7:173-83.

13 Karabatsas CH, Cook SD. Topographic analysis in pellucid marginal corneal degeneration and keratoglobus. Eye 1996;10:451-5.

14 Van Rij G, Waring GO. Changes in corneal curvature induced by sutures and incisions. Am $\mathcal{f}$ Ophthalmol 1984;98:773-83.

15 Wilson SE, Klyce SD. Quantitative descriptors of corneal topography. Arch Ophthalmol 1991;109:349-53.

16 Dingeldein SA, Klyce SD, Wilson SE. Quantitative descripanalysis of photokeratographs. 7 Refract Corneal Surg 1989. 6:372-8. 